\title{
GCMs Derived Projection of Precipitation and Analysis of Spatio-Temporal Variation over N-W Himalayan Region
}

\author{
Dharmaveer Singh $^{* 1}$, R.D. Gupta ${ }^{2}$ and Sanjay K. Jain ${ }^{3}$ \\ 1 GIS Cell, Motilal Nehru National Institute of Technology Allahabad-211004, India \\ 2 Department of Civil Engineering, Motilal Nehru National Institute of Technology, Allahabad- \\ 211004, Uttar Pradesh, India. \\ 3 Scientist-F, Water Resources Systems Division, National Institute of Hydrology, Roorkee-247667, \\ India.
}

\begin{abstract}
The ensembles of two Global Climate Models (GCMs) namely, third generation Canadian Coupled Global Climate Model (CGCM3) and Hadley Center Coupled Model, version 3 (HadCM3) are used to project future precipitation in a part of North-Western $(N-W)$ Himalayan region, India. Statistical downscaling method is used to downscale and generate future scenarios of precipitation at station scale from large scale climate variables obtained from GCMs. The observed historical precipitation data has been collected for three metrological stations, namely, Rampur, Sunni and Kasol falling in the basin for further analysis. The future trends and patterns in precipitation under scenarios $A 2$ and A1B for CGCM3 model, and A2 and B2 for HadCM3 model are analyzed for these stations under three different time periods: 2020's, 2050's and 2080's. An overall rise in mean annual precipitation under scenarios A2 and A1B for CGCM3 model have been noticed for future periods: 2020's, 2050's and 2080's. Decrease, in precipitation has been found under A2 and B2 scenarios of HadCM3 model for 2050's and slight increase for 2080's periods. Based on the analysis of results, CGCM3 model has been found better for simulation of precipitation in comparison to HadCM3 model.
\end{abstract}

Keywords: CGCM3, HadCM3, Statistical downscaling method, Precipitation

\section{INTRODUCTION}

Availability of abundant water on time is a prime concern for agriculture, energy and industrial sectors in India. The country has viewed increase in demand of water due to rapid growth in population and economy. Studies by various authors show that change in patterns of temperature and precipitation due to climate change may amend availability of water along with the risk of increased frequency of droughts and floods (Kumar and Jain 2010). The proper assessment of potential water resources is required in order to maintain continuous water supply to various sectors such as agricultural, industrial, energy and domestic in future (Gosain et al., 2011).

\footnotetext{
* Corresponding author : Dharmaveer Singh, E-mail:veermnnnit@gmail.com
} 
Precipitation determines the magnitude of available water and is an important factor. Knowledge about past and future precipitation along with its variability has scientific as well as practical significance in climate change impact studies. Investigating how change in climate will alter future precipitation and its spatial and temporal variability is an area of active research (Basistha et al., 2009). Generally, assessment of likely future precipitation is done under a climate change scenario (Anandhi et al., 2008). A climate scenario which refers to plausible future climate is a time series of synthetic weather data. These scenarios are based on future emission of greenhouse gases and used to study possible effects of human-induced climate change (Lapp et al., 2009). Uncertainties associated with scenarios are an important issue in scientific communities as it is very intricate to determine nature of future concentrations of greenhouse gasses in atmosphere based on anthropogenic activities (Carter et al., 2001). Scenarios should not be taken as forecasts of future climate as these are constructed to provide sufficient quantitative measures of uncertainty represented with a range of plausible future paths (Lapp et al., 2009). Anandhi et al. (2008) has strongly advocated for using a range of scenarios in climate change impact studies.

Global Climate Models (GCMs), the most credible available tools, are used to simulate state of the present and future climate using transient climate simulations. In a transient simulation, anthropogenic forcings, decided on the basis of IPCC climate scenarios, are changed gradually in a realistic fashion (Anandhi et al, 2008). The decrease in the accuracy of GCMs simulated climate variables has been observed from continental to local scale as they are unable to capture sub-grid scale features and physical dynamics due to their coarse (typically of the order $50,000 \mathrm{~km} 2$ ) spatial resolution (Xu., 1999). This limits the direct applications of GCM's outputs in regional climate change impact studies (Ghosh, 2010; Raghavan et al., 2012; Wilby et al., 2002). A methodology usually known as downscaling is introduced for bridging the gap between the scale of GCMs and required resolution for practical applications. Downscaling methodology broadly can be classified into statistical and dynamical methods (Ghosh, 2010).

Statistical downscaling method is supported by the view; the regional climate is conditioned by large scale climate state and regional/local physiographic features (e.g. topography, landsea distribution and land use/land cover). In this method, large scale atmospheric variables (predictors) of GCMs are related to stationscale climate variables (predictands) based on empirical relationship (Kim et al., 1984; Raje and Mujumdar, 2011; von Storch et al., 2000). The statistical downscaling methods can be classified into 3 categories; weather typing, weather generator and regression method (Wilby and Wigley, 1997). In literature, the strength and weakness of each method is critically analyzed (Bárdossy et al., 2005; Dubrovsky et al., 2004; Fowler et al., 2000; Hua et al., 2010; Kilsby et al., 2007; Mason, 2004; Tripathi et al., 2006 Wilby et al., 1999). In dynamical downscaling method physical processes are simulated at fine scale from host GCMs using a Regional Climate Model (RCM). A horizontal resolution of the order of tens of kilometers is obtained from RCMs over selected area of interests. RCMs accounts use of initial boundary conditions and time dependant lateral meteorological conditions derived from GCMs to provide information at high spatial and temporal scales (Giorgi, 1990; Jones et al., 1995). The complex design and computationally expensive nature of 
RCMs has limited their applications in climate change impact studies (Ghosh and Mishra, 2010; Hewitson and Crane 1996).

The Himalayan mountain systems which are birth place of many perennial river systems such as the Indus, the Ganga and the Brahmaputra have also a strong influence over the climate of Indian sub-continent (Bhutiyani et al., 2007). Hence, a small change in the climate of the Himalaya has a potential to bring devastating effects on the socio-economic survival of millions of people living in these basins. Jain (2012) observed that trend analysis of past precipitation data in India has not revealed any significant extensive change in the patterns so far, but the simulated results derived from GCMs illustrate that in future these patterns are likely to change. These changes would not be uniform over space and time domain as some areas are expected to receive more precipitation and others less. There may be increase in frequency of extreme precipitation events.

Similar trend in precipitation has also been detected over Himalayan region. The northeast region along with eastern and central parts of the Tibetan Plateau has reveled increasing trend in annual precipitation while the western Tibetan region shows decreasing trend (Zhao et al., 2004; Xu et al., 2008). Similarly, the northwestern Himalayan region (northern Pakistan) has experienced an increasing trend while Nepal exhibited no long-term trend in precipitation (Farooq and Khan, 2004; Shrestha et al., 2000). Increase in post-monsoon precipitation has been detected at Dehradun, Pithoragarh and other western Himalayan stations whereas decrease in winter (Pant et al., 1999). Kumar et al. (2005) found an increasing trend in annual precipitation but decreasing trend in monsoon precipitation over Himachal Pradesh, India. The modelled projections have shown a decrease of about $20 \%$ in monsoon precipitation in most parts of Pakistan and in south-eastern Afghanistan by the end of the century. The Tibetan plateau will exhibit increase (10-30\%) in mean annual precipitation by 2080 (IPCC, 2007). Rupa Kumar et al. (2006) observed projected increase of 20 to $30 \%$ in precipitation for the western Himalayan region by the end of $21^{\text {st }}$ century.

Keeping the above in mind, the objective of the present paper is to study the change in patterns of future precipitation under various emission scenarios over North-Western (NW) Himalayan region, India. For this purpose, a software called Statistical Downscaling Model version 4.2 (SDSM 4.2) is used for downscaling of precipitation from large scale climate predictors obtained from third generation Canadian Coupled Global Climate Model (CGCM3) and Hadley Center Coupled Model, version 3 (HadCM3). India. SDSM 4.2 is used to generate single-sites scenarios of daily surface weather variables from large scale climate predictors simulated by GCMs (Wilby et al., 2007). The future patterns and variability in precipitation under scenarios $\mathrm{A} 2$ and $\mathrm{A} 1 \mathrm{~B}$ for CGCM3 model, and A2 and B2 for HadCM3 model are analyzed under three different time periods: 2020's (2011-2040), 2050's (20412070) and 2080's(2071-2099).

\section{STUDY AREA}

The study area is a part of the Sutlej river basin and confined to the State of Himanchal Pradesh, India. The State shares its boundary with four Indian States namely, Jammu and Kashmir from North, Punjab from West, Haryana from South, Uttarakhand from South-East and has 


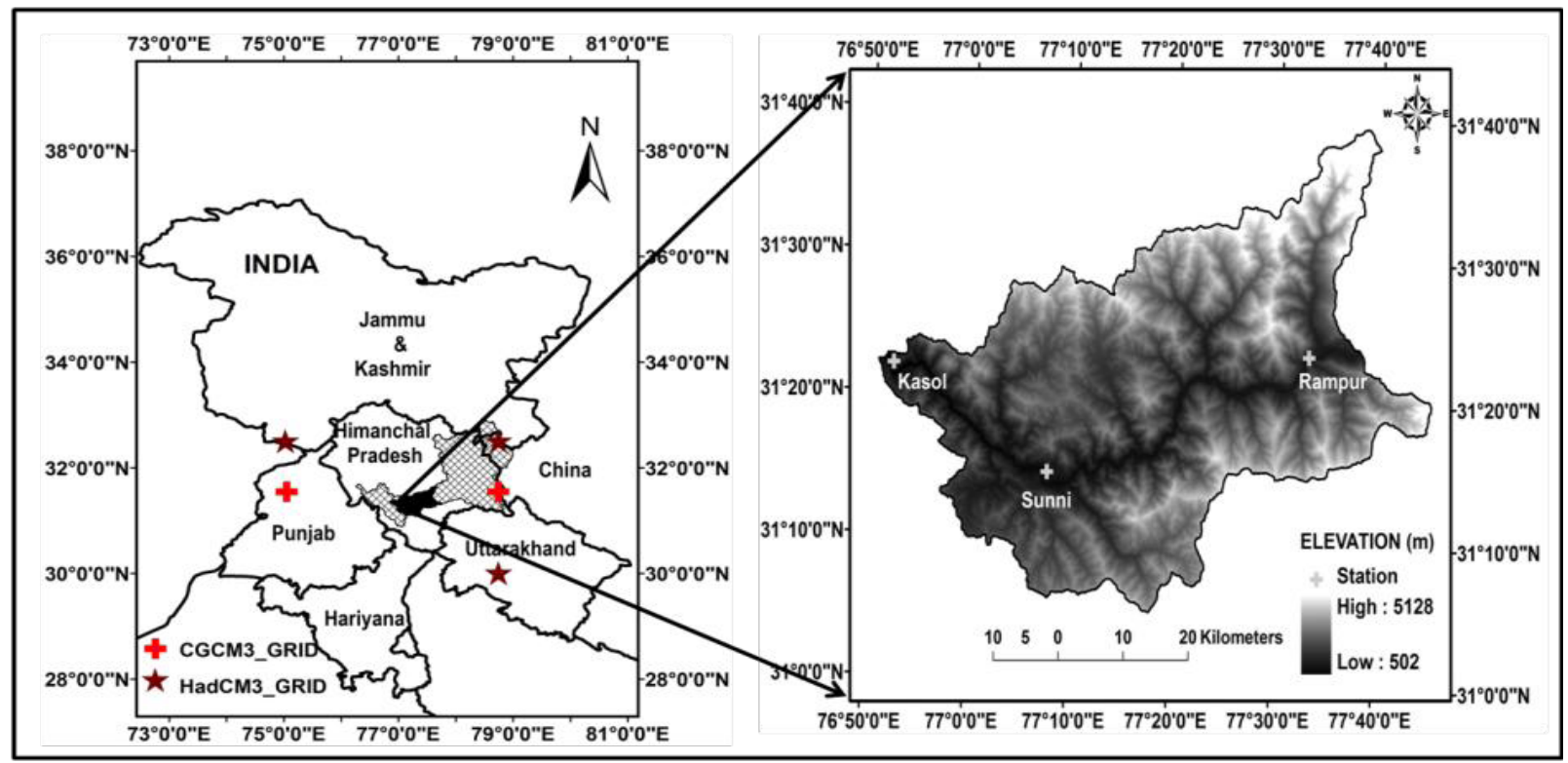

Figure 1: Location map of study area

international border with China (Tibet). It covers a geographical area of $2457 \mathrm{~km} 2$ lying between $31^{\circ} 05^{\prime} 00^{\prime \prime} \mathrm{N}$ to $31^{\circ} 39^{\prime} 26^{\prime \prime} \mathrm{N}$ latitudes and $76^{\circ} 51^{\prime} 11^{\prime \prime} \mathrm{E}$ to $77^{\circ} 45^{\prime} 17^{\prime} \mathrm{E}$ longitudes (Figure 1).

Sutlej river basin is drained by the Sutlej river which originates from Mansarovar- Rakastal lakes near Darma pass in the western Tibet at an elevation of $4,570 \mathrm{~m}$. The basin is characterized by steep slope, dissected topography and high relief features. The altitude in the basin (study area) ranges in between $502 \mathrm{~m}$ to $5128 \mathrm{~m}$. The slope gradually decreases downstream. The major part of the study area exhibits the characteristics of warm and temperate climate. The mean annual rainfall and temperature is $103 \mathrm{~cm}$ and $21.23^{\circ} \mathrm{C}$ respectively.

\section{DATA SETS}

The data acquired from various sources are used throughout the downscaling procedure. The climate station precipitation data (predictand) which is available on daily time step is procured from Bhakra Beas Management Board (BBMB), India for three stations namely, Kasol, Sunni and Rampur. These stations have data series covering the period 1963-2000 for Kasol and 1970-2000 for Sunni and Rampur respectively. Figure 1 also shows the location of stations.

The observed and modelled predictors are obtained from the National Centre for Environmental Prediction/ National Centre for Atmospheric Research (NCEP/ NCAR) reanalysis (Kalnay et al., 1996) and from CGCM3 and HadCM3 models respectively. The NCEP/NCAR reanalysis data sets have a grid-spacing of $1.9^{\circ}$ latitude $\times 1.9^{\circ}$ longitude whereas CGCM3 and HadCM3 have grid resolution of $3.75^{\circ}$ latitude $\times 3.75^{\circ}$ longitude and $2.5^{\circ}$ latitude $\times 3.75^{\circ}$ longitude respectively . The re-gridding of the NCEP/NCAR reanalysis predictors have been performed to conform to the grid-spacing of CGCM3 and HadCM3 models. The standardization of predictors is carried out before statistical downscaling to minimize biases in mean and variance of CGCM3 and HadCM3 predictors with respect 
Table 1: Selection of NCEP/ NCAR predictors using partial correlations and P value statistics

\begin{tabular}{|c|c|c|c|c|c|c|}
\hline \multirow[b]{2}{*}{ Station } & \multicolumn{3}{|c|}{ Precipitation (CGCM3 Model) } & \multicolumn{3}{|c|}{ Precipitation (HadCM3 Model) } \\
\hline & Predictors & $\begin{array}{c}\text { Partial } \\
\text { Correlation(r) }\end{array}$ & $\begin{array}{c}\mathrm{P} \\
\text { value }\end{array}$ & Predictors & $\begin{array}{c}\text { Partial } \\
\text { Correlation(r) }\end{array}$ & $\begin{array}{c}\mathrm{P} \\
\text { value }\end{array}$ \\
\hline \multirow{6}{*}{ Kasol } & $p_{-} v$ & 0.027 & 0.2860 & msl & -0.114 & 0.0000 \\
\hline & p500 & 0.076 & 0.0021 & p5_f & 0.094 & 0.0006 \\
\hline & p5zh & 0.073 & 0.0032 & rhum & 0.149 & 0.0000 \\
\hline & s850 & 0.122 & 0.0000 & & & \\
\hline & shum & 0.081 & 0.0010 & & & \\
\hline & temp & 0.091 & 0.0002 & & & \\
\hline \multirow{8}{*}{ Sunni } & $p_{-} f$ & 0.011 & 0.5168 & p_z & -0.059 & 0.0418 \\
\hline & p500 & -0.14 & 0.0000 & $\mathrm{p}$ _th & -0.022 & 0.3911 \\
\hline & p_th & -0.080 & 0.0047 & $\overline{\mathrm{pzh}}$ & 0.038 & 0.1925 \\
\hline & shum & 0.208 & 0.0000 & p5_u & -0.036 & 0.2152 \\
\hline & & & & p500 & -0.086 & 0.021 \\
\hline & & & & p8_th & 0.048 & 0.0973 \\
\hline & & & & rhum & 0.115 & 0.0000 \\
\hline & & & & temp & 0.095 & 0.0006 \\
\hline \multirow{7}{*}{ Rampur } & msl & 0.062 & 0.0293 & p5_v & -0.061 & 0.0149 \\
\hline & p_th & -0.041 & 0.1570 & temp & 0.064 & 0.0110 \\
\hline & p500 & -0.153 & 0.0000 & & & \\
\hline & p8_z & 0.120 & 0.0000 & & & \\
\hline & p8zh & -0.117 & 0.0000 & & & \\
\hline & s850 & 0.126 & 0.0000 & & & \\
\hline & temp & 0.089 & 0.0012 & & & \\
\hline
\end{tabular}

to that of NCEP/ NCAR reanalysis data. All the predictor variables are normalized over baseline periods i.e., 1961-1990 periods.

The re-gridded and standardized predictors used as the SDSM model input are directly downloaded from the Data Access Integration (DAI) website (http://loki.qc.ec.gc.ca/DAI/ predictors-e.html) for CGCM3 model and Canadian Climate Impacts Scenarios (CCIS) website (http://www.cics.uvic.ca/scenarios/ index.cgi) for HadCM3 model. The predictor variables are available for period 19612100 for CGCM3 model, 1961-2099 for HadCM3 model and 1961-2001 for NCEP/ NCAR. The predictors are simulated under A2 historical GHG (Greenhouse Gas) and aerosol concentration experiment $(20 \mathrm{C} 3 \mathrm{M})$ as well as
Special Report on Emission Scenarios (SRES) $\mathrm{A} 2$ and $\mathrm{A} 1 \mathrm{~B}$ emission scenarios for future run for CGCM3 model and A2 and B2 emission scenarios for HadCM3 model respectively.

\section{METHODOLOGY}

The SDSM 4.2 software, invented by R.L. Wilby and C.W. Dawson (Wilby et al., 2002) has been used to downscale and generate future scenarios of precipitation. It is a windows based decision support tool that is based on statistical downscaling method. In this software, the multiple liner regression is used to establish empirical relationship between predictors and predictands whereas downscaled data is generated stochastically. Therefore, SDSM 
Table 2: Cross correlation between predictors of NCEP/NCAR (CGCM3model)

\begin{tabular}{|c|c|c|c|c|c|c|c|c|}
\hline \multirow[t]{2}{*}{ Station } & \multicolumn{8}{|c|}{ Predictors } \\
\hline & & $\mathrm{p} \_\mathrm{v}$ & p500 & p5zh & s850 & shum & temp & \\
\hline \multirow{6}{*}{ Kasol } & $\mathrm{p} \_\mathrm{v}$ & 1 & -0.01 & 0.14 & -0.10 & 0.20 & 0.14 & \\
\hline & p $\overline{500}$ & -0.01 & 1 & -0.54 & -0.12 & -0.32 & -0.33 & \\
\hline & p5zh & 0.14 & 0.54 & 1 & 0.03 & 0.04 & 0.01 & \\
\hline & s850 & -0.10 & -0.12 & 0.03 & 1 & 0.87 & 0.67 & \\
\hline & shum & 0.20 & -0.32 & 0.04 & 0.87 & 1 & 0.70 & \\
\hline & temp & 0.14 & -0.33 & 0.01 & 0.67 & 0.70 & 1 & \\
\hline \multirow{5}{*}{ Sunni } & & $p_{-} f$ & p500 & p_th & shum & & & \\
\hline & $p_{-} f$ & 1 & 0.10 & 0.34 & 0.63 & & & \\
\hline & p_th & 0.10 & 1 & 0.37 & 0.29 & & & \\
\hline & p500 & 0.34 & 0.37 & 1 & 0.81 & & & \\
\hline & shum & 0.63 & 0.29 & 0.81 & 1 & & & \\
\hline \multirow{8}{*}{ Rampur } & & msl & p_th & p500 & p8_z & p8zh & s850 & temp \\
\hline & msl & 1 & -.03 & -0.10 & -0.10 & -0.08 & -0.11 & 0.05 \\
\hline & p_th & -.03 & 1 & -0.20 & -0.58 & 0.36 & -0.26 & -0.82 \\
\hline & p500 & -0.10 & -0.20 & 1 & -0.16 & 0.12 & 0.82 & 0.90 \\
\hline & p8_z & -0.10 & -0.58 & -0.16 & 1 & -0.19 & -0.35 & -0.28 \\
\hline & p8zh & -0.08 & 0.36 & 0.12 & -0.19 & 1 & 0.23 & 0.17 \\
\hline & $\mathbf{s 8 5 0}$ & -0.11 & -0.26 & 0.82 & -0.35 & 0.23 & 1 & 0.89 \\
\hline & temp & 0.05 & -0.82 & 0.90 & -0.28 & 0.17 & 0.89 & 1 \\
\hline
\end{tabular}

is a hybrid downscaling model comprising a stochastic weather generator and a regression method (Chen et al., 2010). The development of SDSM tool and its characteristics are discussed in literature (Wilby et al., 1998, 1999, 2002; Wilby and Dawson, 2007). The predictor variables selected for downscaling daily precipitation used in the study are shown in bold in Table 1. Further, cross correlation between predictors of NCEP/NCAR is also investigated and it is shown in Table 2 for CGCM3 model. A high positive correlation is observed between predictors such as shum, s850 and temp. This indicates mutual dependency of these predictors with each other.

\section{RESULTS AND DISCUSSIONS}

This section describes the development of SDSM 4.2 for downscaling of precipitation from predictors of NCEP/ NCAR and GCMs. The performance of the model along with downscaled results is discussed for future periods (2020's, 2050's and 2080's) under various emission scenarios (A2, A1B and B2).

\subsection{Development of SDSM Downscaling Model}

The selected predictors from sets of NCEP/ NCAR reanalysis data as given in Table 2 are used to train SDSM 4.2 model. The model is calibrated and validated for downscaling precipitation using 20 years (1963-1982 for Kasol) data, 16 years (1970-1985 for Sunni and Rampur) and 18 years (1983-2000 for Kasol), 15 years (1986-2000 for Sunni and Rampur) data respectively. The statistical parameters such as the monthly average percentage of explained variance (E) and the monthly 
Table 3: Performance statistics of SDSM model during calibration period

\begin{tabular}{lcccccccc}
\hline \multirow{2}{*}{ Station } & \multicolumn{3}{c}{ Precipitation (CGCM3) } & \multicolumn{3}{c}{ Precipitation (HadCM3) } \\
\cline { 2 - 10 } & $\mathbf{E ~ ( \% ) ~}$ & $\begin{array}{c}\text { SE } \\
(\mathbf{m m})\end{array}$ & $\mathbf{R}^{\mathbf{2}}$ & $\begin{array}{c}\text { RMSE } \\
(\mathbf{m m})\end{array}$ & $\mathbf{E} \mathbf{( \% )}$ & $\begin{array}{c}\text { SE } \\
(\mathbf{m m})\end{array}$ & $\mathbf{R}^{\mathbf{2}}$ & $\begin{array}{c}\mathbf{R} \text { RSE } \\
(\mathbf{m m})\end{array}$ \\
\hline Kasol (1963-82) & 11.20 & 0.082 & 0.63 & 3.17 & 5.00 & 0.87 & 0.61 & 3.43 \\
\hline Sunni (1970-85) & 6.40 & 0.088 & 0.41 & 2.13 & 7.30 & 0.88 & 0.37 & 2.42 \\
\hline Rampur (1970-85) & 13.60 & 0.79 & 0.46 & 1.18 & 8.30 & 0.081 & 0.30 & 1.45 \\
\hline
\end{tabular}

Table 4: Performance statistics of SDSM model during validation period

\begin{tabular}{lcccccccc}
\hline \multirow{2}{*}{ Station } & \multicolumn{3}{c}{ Precipitation (CGCM3) } & \multicolumn{3}{c}{ Precipitation (HadCM3) } \\
\cline { 2 - 9 } & E (\%) & $\begin{array}{c}\text { SE } \\
(\mathbf{m m})\end{array}$ & $\mathbf{R}^{\mathbf{2}}$ & $\begin{array}{c}\mathbf{R M S E} \\
\mathbf{( m m )}\end{array}$ & $\mathbf{E ~ ( \% )}$ & $\begin{array}{c}\text { SE } \\
(\mathbf{m m})\end{array}$ & $\mathbf{R}^{\mathbf{2}}$ & $\begin{array}{c}\mathbf{R} \text { RSE } \\
(\mathbf{m m})\end{array}$ \\
\hline Kasol (1983-2000) & 10.40 & 0.084 & 0.58 & 3.54 & 4.80 & 0.87 & 0.57 & 3.34 \\
\hline Sunni (1986-2000) & 5.90 & 0.088 & 0.49 & 1.89 & 7.10 & 0.87 & 0.34 & 2.25 \\
\hline Rampur (1986-2000) & 13.90 & 0.79 & 0.37 & 1.34 & 9.90 & 0.080 & 0.31 & 1.46 \\
\hline
\end{tabular}

average standard error (SE) are used to reflect downscaling results of daily precipitation at each site in the basin. To evaluate the efficiency of model performance during calibration period, coefficient of determination $\mathrm{R}^{2}$ and Root Mean Square Error (RMSE) statistics are used.

The results obtained from calibration show small values of $\mathrm{E}(\%)$ and $\mathrm{R}^{2}$ which reveal the complexity of downscaling station scale precipitation from predictor variables (Table $3)$. The monthly average value of $E(\%)$ for precipitation has been found in between $6.40 \%$ to $13.60 \%$ for CGCM3 model and 5.00(\%) to $8.30(\%)$ for HadCM3 model respectively. The results gained during validation are listed in Table 4.

A comparison of observed daily precipitation with downscaled precipitation has been shown in Figure 2 and 3 for calibration and validation period. The results show that a moderate to poor agreement has been observed between observed and downscaled precipitation values.
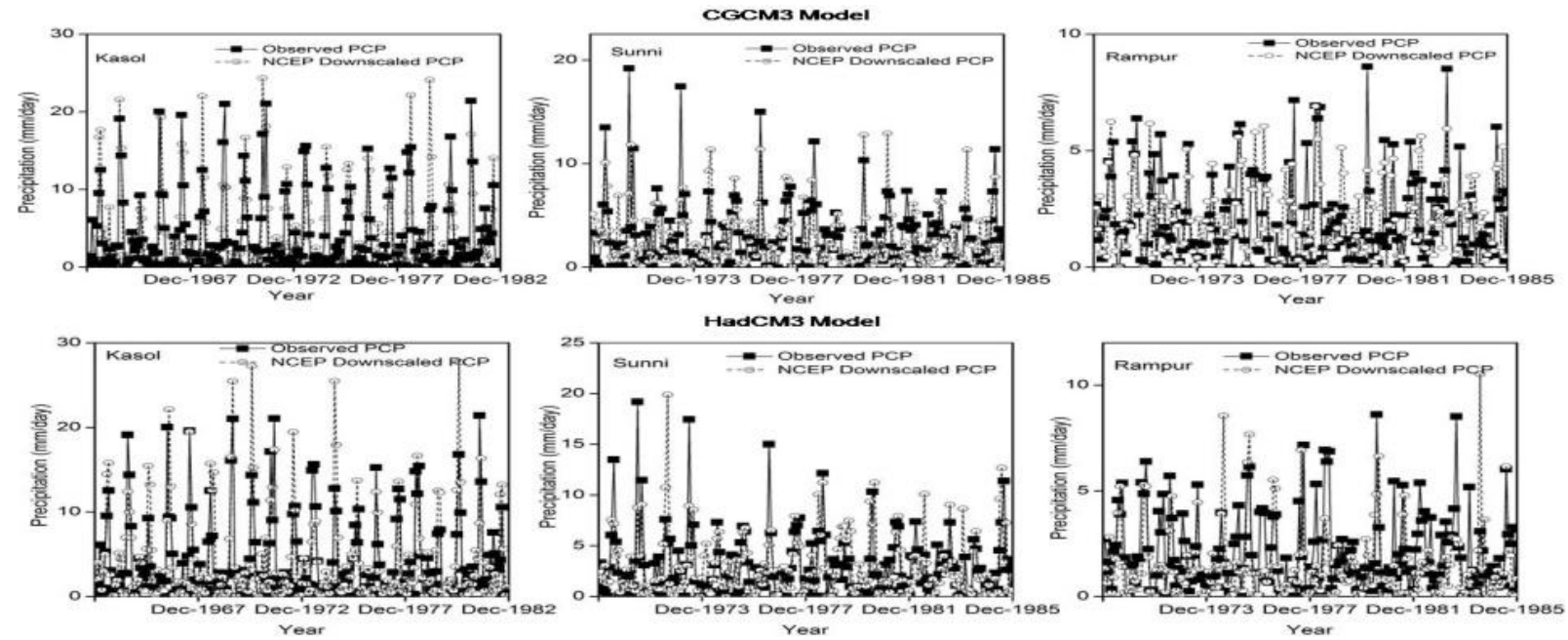

Figure 2: Comparing observed and downscaled values of precipitation for all three stations during calibration period for CGCM3 and HadCM3 models 

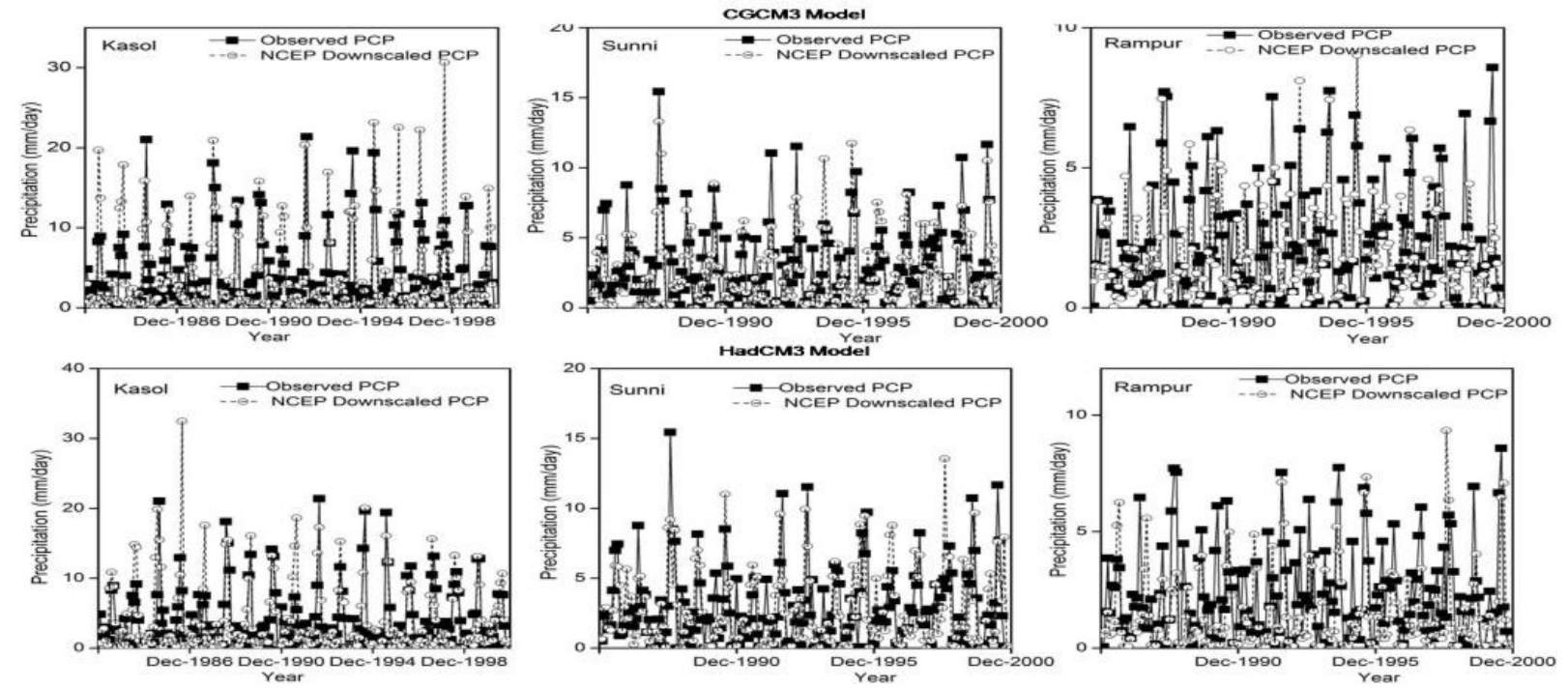

Figure 3: Comparing observed and downscaled values of precipitation for all three stations during validation for CGCM3 and HadCM3 models
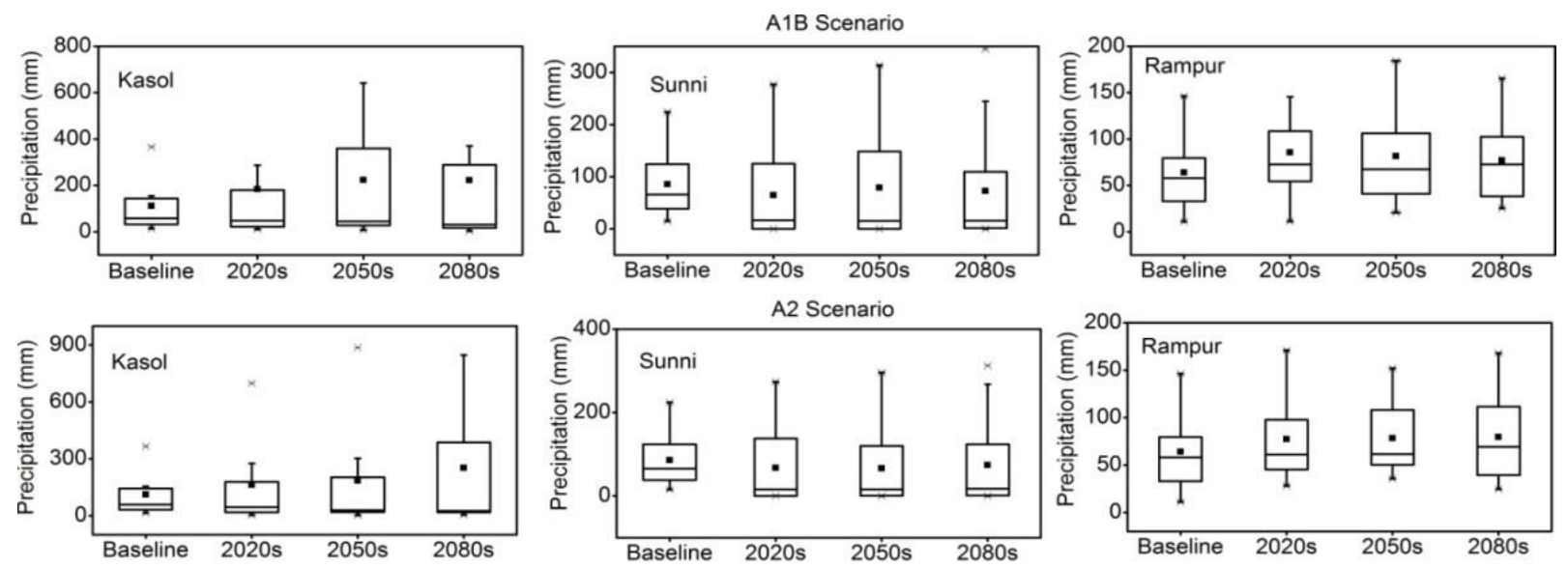

Figure 4: Box plots results from SDSM based downscaling model for the projected precipitation (CGCM3 model). The horizontal line in the middle of the box represents median value while darkened square represents mean value of precipitation data

\subsection{Spatial and Temporal Patterns of Downscaled Precipitation for Future Periods}

The calibrated SDSM model is used to downscale and generate future scenarios of precipitation from predictors of $\mathrm{CGCM} 3$ (SRES A2 and A1B) and HadCM3 (SRES A2 and B2) models in the study region. The pattern of downscaled precipitation is investigated for future periods with a box plot. For this study, the future period is grouped into three time slices; 2020's (2011-2040), 2050's (2041-2070) and 2080's (2071-2099) and each corresponds to span of 30 year periods respectively. The downscaled precipitation is compared with baseline precipitation (1970-2000) to observe change in patterns of precipitation.

The projected precipitation for the future periods (2020's, 2050's and 2080's) has been shown in Figure 4 for the CGCM3 model. 

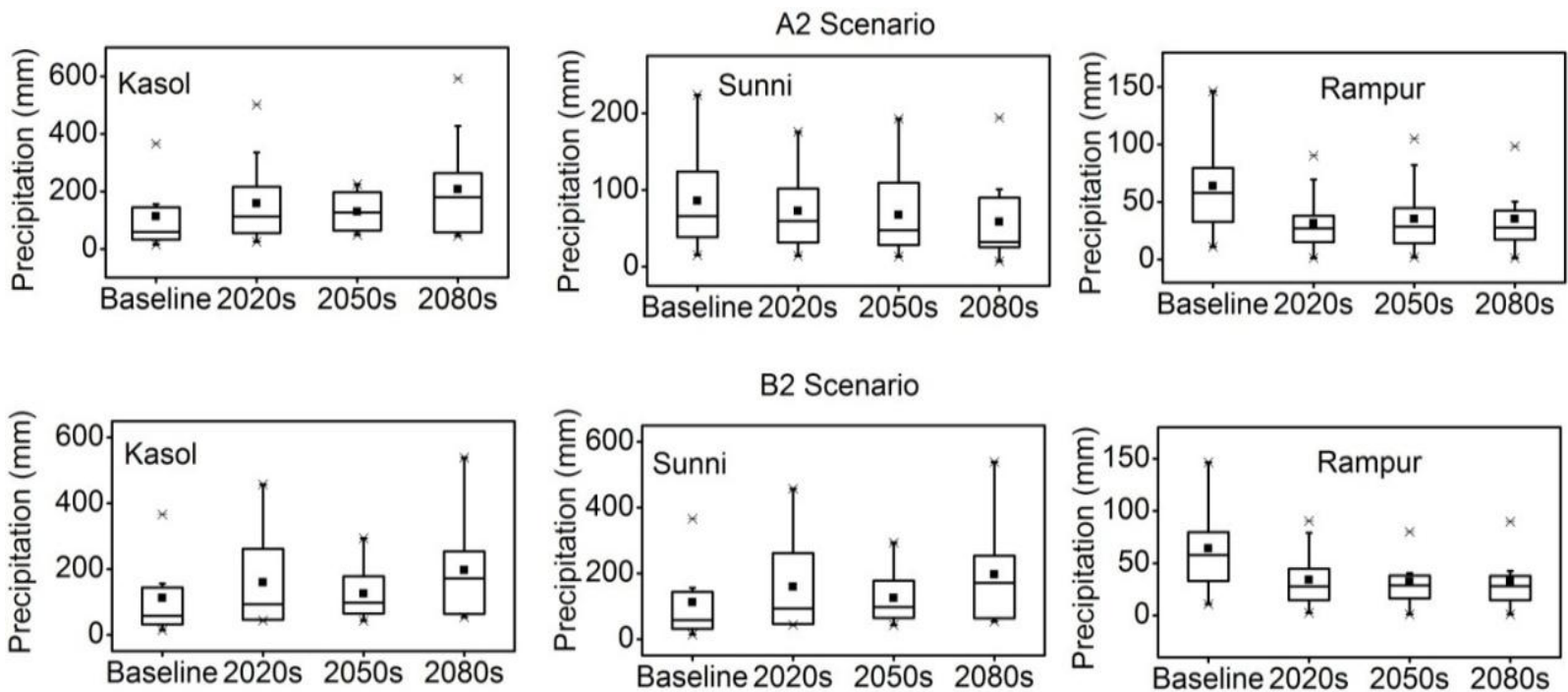

Figure 5: Box plots results from SDSM based downscaling model for the projected precipitation (HadCM3 model). The horizontal line in the middle of the box represents median value while darkened square represents mean value of precipitation data

The increase in future precipitation has been observed at Kasol and Rampur while decrease has been found at Sunni for SRES A2 and SRES A1B scenarios. An overall increase of $5.67 \%, 8.52 \%$ and $18.25 \%$ has been computed in mean annual precipitation in the study area under A1B scenario during 2020's, 2050's and 2080 's whereas it is $9.21 \%, 11.23 \%$ and $13.91 \%$ under A2 scenario respectively. The increase in projected precipitation is higher for A2 scenario as compared to A1B scenario.

The results obtained from HadCM3 model is shown in Figure 5. The decline in amount of simulated precipitation has been found at Sunni and Rampur whereas increase at Kasol for SRES A2 and SRES B2 scenarios. The net change in amount of mean annual precipitation has been computed over study area under SRES A2 and SRES B2 scenarios. The results show increase in magnitude of precipitation under A2 and B2 scenarios for 2080's and decrease for 2050's respectively. This has been found 5.24\% under A2 scenario and $4.57 \%$ under B2 scenario for 2080's and 3.77\% under A2 and 4.08\% under B2 for 2050's. For 2020's, no change in mean annual precipitation has been noticed under A2 whereas it is $0.92 \%$ under B2 scenario. The poor results obtained during calibration and validation suggests that predictors of HadCM3 model are not well simulated. Further, these are unable to capture regional climate dynamics and hence, poorly projected by SDSM model as compared to CGCM3 model.

The seasonal patterns of projected precipitation have been studied and presented in Table 5 for CGCM3 model. The large increase in projected precipitation has been found at Kasol and significant decrease at Sunni during JJA (June, July, August) periods. The unexpected results have been observed at Rampur. The increase in projected precipitation has been shown during JJA periods for A1B emission scenario and decrease for A2 scenario accordingly. The model predicts increase in projected precipitation under SON (September, October, November) periods for all three stations. 
Table 5: Change in projected precipitation during different seasons for CGCM3 model

\begin{tabular}{|c|c|c|c|c|c|c|c|}
\hline \multirow{3}{*}{ Station } & \multirow{3}{*}{ Season } & \multicolumn{6}{|c|}{ Change in Precipitation (cm) } \\
\hline & & \multicolumn{3}{|c|}{ SRES A2 Scenario } & \multicolumn{3}{|c|}{ SRES A1B Scenario } \\
\hline & & 2020's & 2050's & 2080's & 2020's & 2050's & 2080's \\
\hline \multirow{4}{*}{ Kasol } & DJF & -0.76 & -1.95 & -2.74 & 0.41 & 1.42 & 2.14 \\
\hline & MAM & -2.48 & -2.79 & -2.69 & 1.25 & 2.24 & 2.70 \\
\hline & JJA & 19.15 & 28.75 & 49.24 & 25.90 & 29.90 & 41.68 \\
\hline & SON & 4.13 & 5.01 & 12.24 & 4.78 & 18.54 & 7.24 \\
\hline \multirow{4}{*}{ Sunni } & DJF & 1.27 & 0.06 & 0.38 & 0.50 & 2.13 & 0.50 \\
\hline & MAM & -3.40 & -3.36 & -3.39 & 3.52 & 3.56 & 3.43 \\
\hline & JJA & -10.73 & -10.46 & -8.42 & 10.07 & 7.85 & 9.26 \\
\hline & SON & 5.37 & 5.97 & 6.63 & 5.33 & 6.50 & 7.98 \\
\hline \multirow{4}{*}{ Rampur } & DJF & 1.42 & 0.44 & 7.26 & 1.29 & 1.74 & 1.22 \\
\hline & MAM & 3.63 & 8.92 & 4.40 & 0.20 & 1.20 & 1.81 \\
\hline & JJA & -0.18 & -6.24 & -5.83 & 5.29 & 4.23 & 2.17 \\
\hline & SON & 0.47 & 2.60 & 0.41 & 1.91 & 2.27 & 3.60 \\
\hline
\end{tabular}

Table 6: Change in projected precipitation during different seasons for HadCM3 model

\begin{tabular}{|c|c|c|c|c|c|c|c|}
\hline \multirow{3}{*}{ Station } & \multirow{3}{*}{ Season } & \multicolumn{6}{|c|}{ Change in Precipitation (cm) } \\
\hline & & \multicolumn{3}{|c|}{ SRES A2 Scenario } & \multicolumn{3}{|c|}{ SRES B2 Scenario } \\
\hline & & 2020's & 2050's & 2080's & 2020's & 2050's & 2080's \\
\hline \multirow{4}{*}{ Kasol } & DJF & 19.37 & 5.11 & 37.75 & 18.72 & 2.39 & 36.73 \\
\hline & MAM & 22.13 & 6.22 & 9.99 & 24.04 & 6.59 & 8.78 \\
\hline & JJA & -23.99 & -6.99 & -23.52 & -24.52 & -5.84 & -23.06 \\
\hline & SON & 1.03 & 2.48 & 13.78 & 0.57 & 2.13 & 11.38 \\
\hline \multirow{4}{*}{ Sunni } & DJF & -0.023 & -2.02 & -3.37 & -0.65 & -1.51 & -2.23 \\
\hline & MAM & 4.78 & 3.22 & 0.89 & 4.55 & 2.78 & 2.61 \\
\hline & JJA & -7.98 & -6.86 & -6.62 & -6.57 & -5.14 & -6.34 \\
\hline & SON & -1.89 & -1.60 & -1.87 & -1.83 & -1.77 & -1.80 \\
\hline \multirow{4}{*}{ Rampur } & DJF & -3.19 & 0.20 & -2.91 & -3.20 & -3.01 & -3.16 \\
\hline & MAM & -2.30 & -1.94 & -2.21 & -1.66 & -2.19 & -2.36 \\
\hline & JJA & -5.02 & -4.32 & -4.12 & -4.85 & -5.14 & -4.92 \\
\hline & SON & -2.41 & -2.13 & -2.12 & -2.32 & -2.23 & -2.20 \\
\hline
\end{tabular}

On contrary, the projected precipitation obtained from HadCM3 model (Table 6) show significant differences in results that are obtained from CGCM3 model. The amount of precipitation is reduced significantly during JJA periods at Kasol. The decrease in projected precipitation has been observed for future periods at Sunni and Rampur respectively.

\section{CONCLUSION}

In the present paper, a multiple regression based statistical downscaling tool popularly known as SDSM 4.2 is successfully applied to downscale and generate future scenarios of precipitation from predictors of CGCM3 and HadCM3 models in a part of North-Western 
(N-W) Himalayan region, India. The change in projected precipitation has been studied for the time periods; 2020's, 2050's and 2080's for SRES A2 and A1B scenarios (CGCM3 model) and for SRES A2 and B2 scenarios respectively. The seasonal patterns of precipitation are also examined and changes with respect to baseline period are shown.

The results of precipitation downscaling using SDSM are found to be poor for $\mathrm{HadCM} 3$ model as compared to CGCM3 model. The results obtained from CGCM3 model predict an overall increase in precipitation while decrease in precipitation is predicted by HadCM3 model for the future periods in the region. Based on the analysis of results, CGCM3 model has been found better for simulation of precipitation in comparison to HadCM3 model.

\section{APPENDIX: 1}

\section{Abbreviations used in Table 1}

\begin{tabular}{ll}
\hline Predictors & \multicolumn{1}{c}{ Description } \\
\hline msl & Mean sea level pressure \\
p_f & Surface air flow strength \\
p__v & Surface meridional velocity \\
p__z & Surface vorticity \\
p_th & Surface wind direction \\
pzh & Surface divergence \\
p5_f & 500 hpa airflow strength \\
p5_u & 500 hpa zonal velocity \\
p5_v & 500 hpa meridional velocity \\
Predictors & Description \\
p500 & 500 hpa geopotential height \\
p5zh & 500hpa divergence \\
p8_z & 850 hpa vorticity \\
p8_th & 850 hpa wind direction \\
s850 & Relative/Specific humidity at 850 hpa \\
p8zh & 850 hpa divergence \\
rhum & Near surface relative humidity \\
shum & Surface specific humidity \\
temp & Mean temperature at 2 m \\
\hline
\end{tabular}

\section{REFERENCES}

Anandhi, A., Shrinivas, V.V., Nanjundiah, R.S., Kumar, D.N., 2008. Downscaling precipitation to river basin in India for IPCC SRES scenarios using support vector machine. International Journal of Climatology 28 (3), 401-420.

Bardossy, A., Bogardi, I., Matyasovszky, I., 2005. Fuzzy rule-based downscaling of precipitation. Theoretical and Applied Climatology 82 (1-2), 119-129.

Basistha, A., Arya, D.S., Goyal, N.K., 2009. Analysis of historical changes in rainfall in the Indian Himalayas. International Journal of Climatology, 29 (4), 555-572.

Bhutiyani, M. R., Kale, V. S., Pawar, N. J., 2007. Long-term trends in Maximum, minimum and mean annual air temperatures across the northwestern Himalaya during the twentieth century. Climatic Change, 85, 159-177.

Carter, T.R., La Rovere, E.L, Jones, R.N., Leemans, R., Mearns, L.O., Nakicenovic, N., Pittock, A.B., Semenov, S.M., Skea J., 2001. Developing and applying scenarios. In J.J. McCarthy, O.F. Canziani, N.A. Leary, D.J. Dokken \& K.S. White (Eds.), Climate Change 2001: Impacts, Adaptation, and Vulnerability. Contribution of Working Group II to the Third Assessment Report of the Intergovernmental Panel on Climate Change (pp. 145-190), Cambridge University Press, Cambridge.

Chen, S.-T., Yu, P.-S., Tang, Y.-H., 2010. Statistical downscaling of daily precipitation using support vector machines and multivariate analysis. Journal of Hydrology 385 (1-4), 13-22. 
Dubrovsky, M., Buchtele, J., Zalud, Z., 2004. High-frequency and low frequency variability in stochastic daily weather generator and its effect on agricultural and hydrologic modelling. Climatic Change 63 (1-3), 145-179.

Farooq, A.B., Khan, A.H., 2004. Climate change perspective in Pakistan. In A. Muhammed \& L. Stevenson (Eds.), Proceedings of Capacity Building APN Workshop on Global Change Research, (pp39-46), Islamabad, Pakistan.

Fowler, H.J., Kilsby, C.G., O’Connell, P.E., 2000. A stochastic rainfall model for the assessment of regional water resource systems under changed climatic conditions. Hydrology and Earth System Sciences 4 (2), 261-280.

Ghosh, S., 2010. SVM-PGSL coupled approach for statistical downscaling to predict rainfall from GCM output. Journal of Geophysical Research 115, D22102.

Ghosh, S., Mishra, C., 2010. Assessing hydrological impacts of climate change: modeling techniques and challenges. The Open Hydrology Journal 4, 115-121.

Giorgi, F., 1990. Simulation of regional climate using a limited area model nested in a general circulation model. Journal of Climate 3(9), 941-963.

Gosain, A.K., Rao, S., Arora, A., 2011. Climate change impact assessment of water resources of India. Current Science, 101(3), 356-371.

Hewitson, B. C., Crane, R.G., 1996. Climate downscaling: techniques and application. Climate Research 7 (2), 85-95.
Hua, C., Jing, G., Wei, X., Guo, S., Xu, C.Y., 2010. Downscaling GCMs using the Smooth Support Vector Machine Method to predict daily precipitation in the Hanjiang Basin. Advances in Atmospheric Sciences 27 (2), 274-284.

http://loki.qc.ec.gc.ca/DAI/predictors-e.html [Last accessed date 3/02/2012].

http://www.cics.uvic.ca/scenarios/index.cgi [Last accessed date 3/02/2012].

Jain, S. K., 2012. Sustainable water management in India considering likely climate and other changes. Current Science 102(2), 117-188.

Jones, R.G., Murphy, J.M., Noguer, M., 1995. Simulation of climate change over Europe using a nested regional climate model. I. Assessment of control climate, including sensitivity to location of lateral boundaries. Quarterly Journal of the Royal Meteorological Society, 121(526), 1413-1450

Kalnay, E., Kanamitsu, M., Kistler, R., Collins, W., Deaven, D., Gandin, L., Iredell, M., Saha, S., White, G., Woollen, J., Zhu, Y., Chelliah, M., Ebisuzaki, W., Higgins, W., Janowiak, J., Mo, K.C.,, Ropelewski, C., Wang, J., Leetmaa, A., Reynolds, R., Jenne, R., Joseph, D., 1996. The NCEP/NCAR 40-year reanalysis project. Bulletin of the American Meteorological Society, 77(3), 437-471.

Kim, J. W., Chang, J. T., Baker, N. L., Wilks, D. S., Gates, W. L., 1984. The statistical problem of climate inversion: Determination of the relationship between local and large-scale climate. Monthly Weather Review, 112 (10), 2069-2077. 
Kumar, V., Jain, S.K., 2010. Trends in rainfall amount and number of rainy days in river basins of India (1951-2004). Hydrology Research, 42(4), 290-306.

Kumar, V., Singh, P., Jain S.K., 2005, (April). Rainfall trends over Himachal Pradesh, Western Himalaya, India. In G.N., Mathur, A.S., Chawla, \& R.L., Chauhan (Eds), Conference Proceedings, Development of Hydro Power Projects - A Prospective Challenge (II-63-II-71), organized by CBIP \& HPSEB, Shimla, New Delhi, India.

Kilsby, C.G., Jones, P.D., Burton, A., Ford, A.C., Fowler, H.J., Harpham, C., James, P., Smith, A., Wilby, R.L., 2007. A daily weather generator for use in climate change studies. Environmental Modelling and Software, 22(12), 1705-1719.

Lapp, S., Sauchyn, D., Toth, B., 2009. Constructing scenarios of future climate and water supply for the SSRB: Use and limitations for vulnerability assessment. Prairie Forum (Guest Issue), 34(1), 153180

Mason, S.J., 2004. Simulating Climate over Western North America Using Stochastic Weather Generators. Climatic Change, 62(1-3), 155-187.

Pant, G.B., Rupa, Kumar, R.R., Borgaonkar, H.P., 1999. Climate and its long-term variability over the western Himalaya during the past two centuries. In S.K., Dash, \& J., Bahadur, (Eds). The Himalayan Environment (pp. 171184), New Age International (P) Ltd., Publishers: New Delhi, India.
Raghavan, S.V., Vu, M.T., Liong, S.Y., 2012. Assessment of future stream flow over the Sesan catchment of the Lower Mekong Basin in Vietnam. Hydrological Process, 26 (4), 3661-3668, doi: 10.1002/ hyp. 8452

Raje, D., Mujumdar, P. P, 2011. A comparison of three methods for downscaling daily precipitation in the Punjab region. Hydrological Process, 25(23), 35753589 .

Rupa Kumar, K. R., Sahai, A. K., Krishna, K. K., Patwardhan, S. K., Mishra, P. K., Revadkar, J. V., Kamala, K., Pant, G. B., 2006. High resolution climate change scenario for India for the $21 \mathrm{st}$ century. Current Science 90 (3), 334-345.

Shrestha, A.B., Wake, C.P., Dibb, J.E., Mayyewski, P.A., 2000. Precipitation fluctuations in the Nepal Himalaya and its vicinity and relationship with some large-scale climatology parameters. International Journal of Climatology 20(3), 317-327.

Tripathi, S., Srinivas, V.V., Nanjundiah, R.S., 2006. Downscaling of precipitation for climate change scenarios: a support vector machine approach. Journal of Hydrology 330 (3-4), 621-640.

von Storch, H., Langenberg, H., Feser, F., 2000. A spectral nudging technique for dynamical downscaling purposes. Monthly Weather Review 128 (10), 3664 3673.

Wilby, R.L., Hassan, H., Hanaki, K., 1998. Statistical downscaling of hydrometeorological variables using general circulation model output. Journal of Hydrology 205 (1-2), 1-19. 
Wilby, R.L., Hay, L.E., Leavesly, G.H., 1999. A comparison of downscaled and raw GCM output: implications for climate change scenarios in the San Juan River Basin, Colorado. Journal of Hydrology, 225 (12), 67-91.

Wilby, R.L., Dawson, C.W., Barrow, E.M., 2002. SDSM - a decision support tool for the assessment of regional climate change impacts. Environmental Modelling \& Software, 17(2), 147-159.

Wilby, R.L., Dawson, C.W., 2007. SDSM User Manual- A Decision Support Tool for the Assessment of Regional Climate Change Impacts. Retrieved from https://copublic. lboro.ac.uk/cocwd/SDSM/main.html [Last accessed date 17.11.2011.
Wilby, R.L., Wigley, T.M.L., 1997.Downscaling general circulation model output: a review of methods and limitations. Progress in Physical Geography 21(4), 530-548.

Xu, Y.C., 1999. From GCMs to river flow: a review of downscaling methods and hydrologic modelling approaches. Progress in Physical Geography, 23(2), 229-249.

Xu, Z., Gong, T., Liu, C., 2008. Decadal trends of climate in the Tibetan Plateau - regional temperature and precipitation. Hydrological Processes, 22 (16), 30563065.

Zhao L, Ping C L, Yang D Q et al., 2004. Change of climate and seasonally frozen ground over the past 30 years in Qinghai-Tibetan plateau, China'. Global and Planetary Change, 43, 19-31. 